\title{
Benefits of life in a science incubator
}

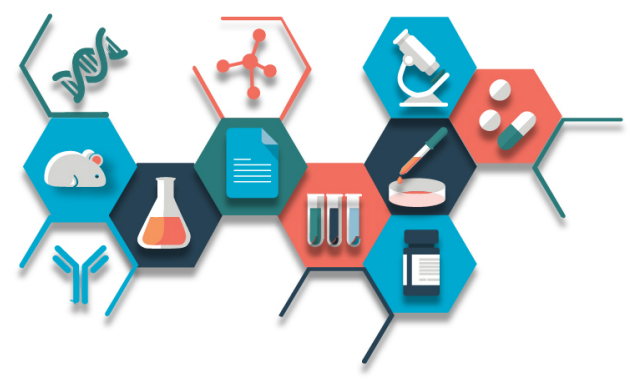

\author{
Michael S Holzwarth*,1 \\ ${ }^{1}$ Department of Chemistry, Actavalon Inc., 3210 Merryfield Row, San Diego, CA 92121, USA \\ *Author for correspondence: mholzwarth@actavalon.com
}

\section{"One crucial aspect of success lies in the fact that incubators handpick start-ups to select the most promising candidates."}

First draft submitted: 22 February 2019; Accepted for publication: 13 March 2019; Published online: 10 June 2019

Keywords: biotech $\bullet$ incubator $\bullet$ life science $\bullet$ start-up

Biotech start-up companies that have resided in life science incubators are significantly more successful than young businesses that stand alone. The effect of an incubator is staggering, transforming a $90 \%$ failure rate into an $88 \%$ success rate for the companies that reside there [1-3]. But what are the underlying reasons for such a remarkable turnaround?

One crucial aspect of success lies in the fact that incubators handpick start-ups to select the most promising candidates. During the initial vetting process, they check, among other criteria, whether the research idea has a reasonable chance of success and if the product has market potential. Therefore, it makes sense that resident companies are more likely to have a higher success rate. However, this is only one part of the story.

All life science start-up companies face countless obstacles on their way to start conducting their research and developing their products. App developers can do their job in a coffee shop around the corner, without the need for significant upfront investment. On the contrary, starting a life science company requires laboratory space and significant seed funding [2]. One way to get laboratory space is to rent it in one of the various life science incubators. Many traditional pharmaceutical companies, as well as nonprofits and other organizations, have realized the potential life science incubators offer and therefore, many of them have established their own, like Pfizer's four Centers for Therapeutic Innovation (CTI) or Johnson \& Johnson Innovation's 12 JLABS. Through this strategy, traditional pharmaceutical companies can avoid the high costs of exploratory research until proof of concept has been shown and can better understand the innovation of the research being done within their incubators. One might wonder why pharmaceutical companies would support such a selfless act and would ask the question: 'What is the catch?' The answer depends on the incubator. For example, Pfizer's CTI jointly owns the research project until the drug enters the clinical phase $[4,5]$. This goes hand-in-hand with access to Pfizer's resources and a close collaboration with the CTI team. The JLABS on the other hand has a 'nostrings attached' policy where researchers can partner with whichever company they choose, and an equity stake is not required [6]. Residents in the JLABS incubator have access to the knowledge and expertise of Johnson \& Johnson through JPAL mentors and can choose to collaborate with J\&J down the road. Whichever model is better depends on the access to mentorship and resources an entrepreneur is looking for to get their product developed and whether or not they would exchange equity in return for incubator access if required.

But what does it actually mean for a company to be nursed in a life science incubator? One of the obvious advantages is the flexibility in the space that can be rented from the incubator. A growing company might change their demands on required lab and office space on a monthly basis. Incubators offer the opportunity to rent only the space a company needs at the moment and more space can be added later on. This leads to lower costs and avoids big moves to a different building when the start-up company grows.

A hurdle many life science companies face are all of the regulations that they need to be in compliance with, including safety regulations, standard operating procedures, waste disposal, environmental agencies and more. In incubators, the support staff is extremely knowledgeable and always happy to help. Therefore, the bureaucratic burden for the residents is reduced and established protocols from the incubator can be implemented. Additionally, 
the luxury of having janitorial staff and shipping and receiving personnel cannot be understated. The existence of these services ultimately frees up time for research, the task an early stage company should focus on.

On top of this, life science incubators offer shared instruments like plate readers, centrifuges and HPLC systems that are available onsite. Resident companies do not need to acquire every single piece of equipment, which reduces costs and saves time during the setup of laboratory space. Although the suggestion of sharing an instrument with scientists from other companies may raise concerns of walk-up availability, the benefits include the additional support of other knowledgeable individuals who may assist if problems with the instrument arise.

Vendors have also identified densely populated incubators as a profitable target for potential sales. Incubators are, therefore, popular sites for vendors to lend and showcase specialized equipment in seminars and onsite demonstrations. In general, sales representatives are much more eager to visit incubators and get in touch with residents, making it easy to build lasting relationships and work closely together to get the best products for the best prices.

Most incubators offer some sort of mentorship to increase the chance of the start-up companies being successful. Some incubators have experienced researchers and managers meeting with the start-up companies on a regular basis to give advice on topics like business plans, research goals and fundraising. In addition to mentorship programs, it is common for incubators to host educational and networking events. For example, some events focus on funding opportunities; therefore, a diversity of investors from patient foundations to venture capital firms are invited to give presentations and meet with individuals from the start-ups in order to discover mutual interests. For resident companies, this offers an additional chance to secure sources of funding. There are countless other categories of events that occur, ranging from presentations on how to find the perfect building for your growing company to workshops on how to protect IP, which help start-ups to flourish and grow. Networking is one of the most important advantages and therefore, many incubators have different occasions to get to know your neighbor. From breakfast to lunch to after-work happy hours, there are many opportunities to meet new people and to learn about their breakthrough research.

One of the most important reasons why working in a life science incubator is extremely useful is the quality of residents. Everyone has been in situations where they do not know how to use a specific instrument or when they run out of materials in the middle of an important experiment. In life science incubators, there is a good chance that an employee from another company knows the piece of equipment in question and is happy to help or can lend materials out during critical times. The same is true if someone wants to run an assay they have never run before, a researcher in the incubator may have experience with it and is more than willing to give valuable advice. It is necessary to mention that all the information exchanged is limited to general advice and never specific to the project in order to protect each company's intellectual property. Mutual support helps to lessen the daily struggles occurring in a standalone start-up company and is one key to success in the world of life science incubators.

The social aspect of an incubator is another invaluable benefit. The shared coffee corner turns into a place to meet various people from CEOs to bench scientists and they exchange a few friendly words to make each other's day better. The collaborative and welcoming atmosphere lifts up the mood and makes people more motivated to strive in their jobs. And if once in a while an experiment fails, a coffee break with other residents can mean everything to patch up the wounds and go back with motivation to get the experiment working.

Another strength of incubators is the diversity of the people within it. With scientists from all over the world working under one roof, the opportunity to learn about other cultures and understanding life in different environments is extremely rewarding. Studies have shown that diversity at the workplace has several benefits resulting ultimately in more successful and more effective companies [7-9]. Therefore, resident companies profit from innovation through diversity as well as from the greater range of talent that is attracted to a multicultural incubator. In terms of diversity, it is also worth mentioning that start-up companies in incubators have more women in C-level positions than traditional pharmaceutical companies. For example, JLABS states that $23 \%$ of JLABS companies have women as CEOs. In contrast, less than $1 \%$ of traditional life science companies have female CEOs [10].

Indeed, life science incubators provide the optimal conditions for start-up companies to grow and be successful, resulting in significantly higher success rates. The diverse and collaborative atmosphere sets the right tone for innovation and success and therefore, life science incubators will remain an essential part of the future of drug discovery. 


\section{Financial \& competing interests disclosure}

The author is currently a resident of the JLABS life science incubator in San Diego, CA, USA. The author has no other relevant affiliations or financial involvement with any organization or entity with a financial interest in or financial conflict with the subject matter or materials discussed in the manuscript. This includes employment, consultancies, honoraria, stock ownership or options, expert testimony, grants or patents received or pending, or royalties.

No writing assistance was utilized in the production of this manuscript.

\section{Open access}

This work is licensed under the Attribution-NonCommercial-NoDerivatives 4.0 Unported License. To view a copy of this license, visit http://creativecommons.org/licenses/by-nc-nd/4.0/

\section{References}

1. Lo C. Counting the cost of failure in drug development. Pharmaceutical Technology, London, UK (2017). www.pharmaceutical-technology.com/features/featurecounting-the-cost-of-failure-in-drug-development-5813046/

2. Herper M. The cost of developing drugs is insane. That paper that says otherwise is insanely bad. Forbes, NJ, USA (2017). www.forbes.com/sites/matthewherper/2017/10/16/the-cost-of-developing-drugs-is-insane-a-paper-that-argued-otherwise-was-insanel y-bad/\#36b9de942d45

3. Tomlinson C. Health care requires a special kind of incubator. Houston Chronicle, TX, USA (2018). www.houstonchronicle.com/business/columnists/tomlinson/article/Health-care-requires-a-special-kind-of-incubator-13340591.php

4. Thermal Product Solutions. Think: thermal: incubators - an innovative way to accelerate early drug development (2017). www.thermalproductsolutions.com/blog/tps/incubators-an-innovative-way-to-accelerate-early-drug-development

5. Pfizer centers for therapeutic innovation. Translating leading science into the clinic (2019). www.pf izercti.com/system/files/page_files/CTI\%20Brochure\%20121113.pdf

6. Johnson \& Johnson Innovation. The JLABS formula (2018). jlabs.jnjinnovation.com/services/jlabs-formula

7. Shemla M. Why workplace diversity is so important, and why it's so hard to achieve. Forbes, NJ, USA (2018). www.forbes.com/sites/rsm discovery/2018/08/22/why-workplace-diversity-is-so-important-and-why-its-so-hard-to-achieve/\#7b3aebad3096

8. Abreu K. The myriad benefits of diversity in the workplace. Entrepreneur, CA, USA (2014). www.entrepreneur.com/article/240550

9. Rock D, Grant H. Why diverse teams are smarter. Harvard Business Review, MA, USA (2016). hbr.org/2016/11/why-diverse-teams-are-smarter?autocomplete=true

10. Johnson \& Johnson Innovation. The JLABS formula (2017). jlabs.jnjinnovation.com/videos/jlabs-5-year-anniversary 